\title{
Effect of particle size and moisture content on cassava root pellet fuel's qualities follow the acceptance of pellet fuel standard
}

\author{
Sonthi Warajanont, Nitipong Soponpongpipat \\ Dept. Mechanical Engineering, Silpakorn University, Nakornpathom, Thailand \\ Email address: \\ son_sonthi@yahoo.co.th (S. Warajanont),nitipongsopon@hotmail.com (N. Soponpongpipat)
}

\section{To cite this article:}

Sonthi Warajanont, Nitipong Soponpongpipat. Effect of Particle Size and Moisture Content on Cassava Root Pellet Fuel'S Qualities Follow the Acceptance of Pellet Fuel Standard, International Journal of Renewable and Sustainable Energy. Vol. 2, No. 2, 2013, pp. 74-79. doi: $10.11648 /$ j.ijrse.20130202.17

\begin{abstract}
This research studied about pellet fuel standards around the world and the effect of particle size and moisture content on cassava pellet fuel's qualities. The sample pellet fuel from cassava root was produced in flat die pellet mill at controlling temperature $80-90{ }^{\circ} \mathrm{C}$. The studying parameters were particle size and moisture content. The particle size was defined by hammer mill screen sizes : 1, 4, and 10 millimeters. In the part of moisture content was defined by quantities of water addition in cassava root : 10,20, and $30 \%$ by raw cassava root mass. All different compound samples, cassava root pellet fuel were tested by PFI standard (The United State of America's pellet fuel standard). The qualities of pellet fuel were diameter, length, moisture content, durability, fine, heating value, and bulk density. The result from testing shown that all cassava root pellet fuel samples passed the criterion of PFI standard and other pellet fuel standards. From this result indicated that the particle size and moisture content didn't influence with all different compound cassava root pellet fuel samples.
\end{abstract}

Keywords: Cassava Root, Pelletization, Pellet Fuel Standard, Pellet Fuel

\section{Introduction}

Nowadays, Thailand is confronting the crisis of energy from economic expansion. The energy researchers consider on Thailand that is the agricultural country. Each year has the huge of agricultural residues from agricultural harvest. The agricultural residues are rice straw, rice husk, sugar cane, palm branch, and etc [1]. All of agricultural residues are taken to use as alternative energy. However, the use of agricultural residues, which is the biomass without the improvement process, has some disadvantages. For example, the high moisture content in raw biomass causes instability of combustion. A problem also occurs when raw biomass is moved from its source to the storage area. With the big size and heavy weight of raw biomass as well as its different shape, length, and size, the transportation takes a lot of time, while each time of transportation, a small quantity of biomass can be moved [2]. Moreover, there is a problem in the design of combustion chamber. However, all mentioned problems can be solved with pelletization that is a way to improve raw biomass by using enough compressive force on particles contributing to the form of pellet. Pelletization causes improved biomass to have the same size and shape, contributing to the decrease of its volume, storage area, and a cost of transportation. The products from pelletization processes are called "pellet fuel".

The pellet fuel is used in the most western countries such as Sweden, Italy, German, Switzerland, United kingdom, and United State [3-5]. The major application of pellet fuel is the thermal energy : the using for the household heater on winter, the using for boiler fuel in the factory, and etc.

The important thing for pellet fuel is quality standards that define and indicate about physical property and chemical property of pellet fuel. These properties are diameter, length, fine, ash, bulk density, durability, heating value and the element component in fuel [2-22]. So, the most researchers have studied about parameters that effect on pellet fuel qualities such as particle size, moisture content, storage time, compress force, the thickness of pellet machine die and other parameters [3], [7-17].

In this paper gives the result about effect of particle size and moisture content on cassava root pellet fuel's qualities and the comparison of cassava root pellet fuel sample with the pellet fuel standard. 


\section{Review of Related Research}

\subsection{Production Process of Pellet Fuel}

Biomass pellet production process is developed from the process of the animal food industry. The process starts from putting biomass in the ring die press machine with the roller pressing the biomass through the small holes around the ring die. Later, the pressed biomass will be cut to pieces with the same length and become to biomass pellet [6]. Nowadays, the pelletization process requires many steps namely gathering the biomass from agricultural area and other sources, dehumidifying, biomass milling, biomass modifying before pelletizing, pelletization, cooling, screening, and pellet's packaging [3]. The pelletization process can be explained in details as follows.

Gathering the raw biomass from agricultural area and other sources [7]. This step uses tractor or agricultural utility cart to store it in the form of cubic, or sometimes it is rolled and stored in the raw material storage area. In case of many kinds of biomass existing together, it is categorized and stored in each container. Each will be mixed together with the consideration on the possibility and suitability before dehumidifying.

Dehumidifying means removing of the water from the biomass by controlling its moisture at $10-15 \%$ by weight [3]. This step requires the drying machine with the temperature range of $60-140{ }^{\circ} \mathrm{C}$ depending on drying technique, drying media, raw material, temperature, and residence time. There are many kinds of drying machines such as rotary drum dryer, flash dryer, and spouted bed dryer [8].

Biomass milling is a way to reduce the biomass size with the milling machine whose screen size is $1 / 4$ or $5 / 16$ inches or about 3 millimeters. The size of biomass after being milled must not be bigger than the pellet's diameter. However, if the size is too small, the fuel pellet might be contaminated when it is formed [3].

Pelletization is to form the milled biomass with pelletization machine. There are two kinds of this machine namely flat-die and vertical mounted ring-die. Before the pelletization starts, the water must be added to stimulate lignin in the biomass to absorb the water. After the lignin absorbs the water, the small particles of biomass will be combined together. The compressive force between roller and pellet mill die is required to form the pellet [3].

Cooling is to reduce the temperature of the pelletized fuel as it has the high temperature and softness. It is necessary to reduce the temperature so that the fuel pellet will be hard and durable for the transportation. The temperature will be reduced from $90{ }^{\circ} \mathrm{C}$ to $25{ }^{\circ} \mathrm{C}$.

Screening is a process to separate the fuel pellet from the dust that will be returned to the producing process. The separated fuel pellet will be moved to storage bag [3]. The high quality biomass pellet contains the dust not more than $0.5 \%$ of the pellet.

Pellet's packaging is done automatically. This process is the last stage of pelletization before the fuel is distributed.

\subsection{The Parameters Affecting the Pellet Fuel Qualities}

From the previous study, it was found that moisture, and particle size affected the qualities of biomass pellet [6]. Moreover, there is a lot of research further studying the effect of compressive force, temperature, storage time, die thickness, and hammer mill screen size on biomass pellet properties.

The moisture content of raw biomass has an influence on net calorific value, combustion efficiency [9], bulk density, and durability index. In the case of bulk density, a higher moisture content cause a lower bulk density of biomass pellet. Moreover, durability index of biomass pellet decrease when moisture content of biomass pellet increase [10].

It was found that a large particle size causes cracks and fracture in pellet [11].

The hammer mill screen size has a role in specifying the size of the biomass after being milled. The pellet formed from the ground biomass has more mechanical durability than the pellet formed from the coarsely ground biomass [10].

The die thickness refers to the thickness of the pelletization machine's part that is an iron plate with holes like the honeycomb. The die is used for pressing the raw biomass through to become pellet. There are two kinds of frame that are circle frame for vertical pelletization machine and ring die for radius pelletization machine. The thicker die results in enhancing of durability, the evidence was found in pellet of wheat straw, corn stover, and sorghum stalk [10].

Compressive force is the force from the pressing head of pelletizing machine on the biomass. From the study, it was found that when the compressive force increased, the length and the density of the pellet were increased [12].

The die temperature for the pelletization must be prepared before the process starts. The die is warmed beforehand at the temperature of $90{ }^{\circ} \mathrm{C}$ to ensure that lignin starts melting and mix with other particles of the biomass, contributing to the ability to form the pellet [6], [14-15].

Storage time of raw biomass is another important factor for pelletization. The raw biomass with long storage time causes more energy consumption to form the pellet than the fresh biomass with the short time of storage. It was also found that the pellet from the long time storage biomass had lower mechanical durability and higher bulk density than the pellet formed from the fresh biomass because the amount of fat and resin affecting the bulk density decreased [16].

\subsection{The Potential of Biomass in Thailand}

Thailand is one of the important agricultural countries in the world. More than 50 percent of people in Thailand have agricultural occupation. The agricultural residues from agricultural products are rice straw, rice husk, sugarcane, and etc. From Thailand agricultural residues approximation in 2009 has been shown the potential of agricultural residues production in Table 1 . 
Table 1. Spatial biomass potential of Thailand in 2009

\begin{tabular}{|c|c|c|c|c|}
\hline Type & Product (tons) & Biomass & $\begin{array}{l}\text { Amount of agri- } \\
\text { cultural residues } \\
\text { (tons) }\end{array}$ & $\begin{array}{l}\text { Heating } \\
\text { value } \\
\text { (MJ/kg } \\
\text { ) }\end{array}$ \\
\hline \multirow{2}{*}{ Sugarcane } & \multirow{2}{*}{$66,816,446.00$} & trash & $4,190,794.31$ & 14.40 \\
\hline & & leaves & $13,439,727.21$ & 17.39 \\
\hline \multirow{2}{*}{ Rice } & \multirow{2}{*}{$31,508,364.00$} & husk & $3,510,598.90$ & 14.27 \\
\hline & & straw & $25,646,547.96$ & 10.24 \\
\hline \multirow[t]{2}{*}{ Soybean } & \multirow[t]{2}{*}{$190,480.00$} & $\begin{array}{l}\text { haulm/shuck/le } \\
\text { aves }\end{array}$ & $170,383.17$ & 19.44 \\
\hline & & bunch & $1,024,868.34$ & 17.86 \\
\hline \multirow[t]{3}{*}{ Palm oil } & \multirow[t]{3}{*}{$8,162,379.00$} & leaves & $162,970.06$ & 17.62 \\
\hline & & shell & $38,959.04$ & 18.46 \\
\hline & & stalk & $2,203,740.00$ & 9.83 \\
\hline \multirow{3}{*}{ Cassava } & \multirow{3}{*}{$30,088,025.00$} & haulm & $2,439,236.19$ & 18.42 \\
\hline & & roots & $1,834,466.88$ & 18.42 \\
\hline & & stalk & $628,990.82$ & 15.40 \\
\hline \multirow[t]{2}{*}{ Coconut } & \multirow[t]{2}{*}{$1,380,980.00$} & bract & $464,250.95$ & 16.23 \\
\hline & & shell & $128,936.58$ & 17.93 \\
\hline Rubber tree & $3,090,280.00$ & limb/stalk & $312,118.28$ & 14.98 \\
\hline Total & $145,853,073.00$ & & $59,539,905.20$ & \\
\hline
\end{tabular}

From Table 1. Show data about spatial biomass potential of Thailand in 2009. The data was considered to select one type of agricultural residues for biomass using improvement as pellet fuel. In this research considered to use cassava root for studying because cassava root has many quantities and high heating value [17].

\section{Methodology of Research}

\subsection{Finding and Accumulating about Pellet Fuel Stan- dards}

Pellet fuel standards are in this research were found and accumulated from Industrial standards office, ministry of Industry, Thailand and pellet fuel websites. The pellet fuel standards were fond such as PFI (United State), ONORM M1735 (Australia), SS 187120 (Sweden), DIN 51731 (German), CTI-R 04/5 (Italy), and ITEBE (France) [5]. The standard in each country is beneficial for commercial production for exporting the biomass pellet fuel to overseas. Table 2. summarized the specification of pellet fuel qualities in each country.

Table 2. The summarized specification of pellet fuel qualities in each country.

\begin{tabular}{|c|c|c|c|c|c|c|c|}
\hline Pellet fuel standards & Diameters (mm) & Length (mm) & $\begin{array}{l}\text { Durability } \\
(\%)\end{array}$ & Fine $(\%)$ & $\begin{array}{l}\text { Bulk density } \\
\text { (MJ/kg) }\end{array}$ & $\begin{array}{l}\text { Moisture content } \\
(\%)\end{array}$ & $\begin{array}{l}\text { Heating value } \\
(\mathrm{MJ} / \mathrm{kg})\end{array}$ \\
\hline $\begin{array}{l}\text { Austria } \\
\text { (ONORM M } 7135\end{array}$ & $4-10$ & $\leq 100$ & - & $<2.3$ & - & $<10$ & $\geq 18.00$ \\
\hline $\begin{array}{l}\text { Sweden } \\
\text { (SS 187120) }\end{array}$ & $4-6$ & $20-30$ & - & $<0.8$ & $\geq 600$ & $\leq 10$ & $\geq 16.90$ \\
\hline $\begin{array}{l}\text { Italy } \\
\text { (CTI-R 04/5) }\end{array}$ & $6-8$ & $30-40$ & $\geq 97.70$ & $\leq 1$ & $620-720$ & $<10$ & $\geq 16.90$ \\
\hline $\begin{array}{l}\text { France } \\
\text { (ITEBE) }\end{array}$ & $6-10$ & $10-30$ & - & - & $>650$ & $<10$ & $>17.02$ \\
\hline $\begin{array}{l}\text { German } \\
\text { (DIN 51731) }\end{array}$ & $4-10$ & $<20-50$ & - & $<2.3$ & - & $<10$ & $15.60-19.60$ \\
\hline USA (PFI) & $5.84-7.25$ & $\leq 38.10$ & $\geq 95$ & $\leq 1$ & $596.6-722.2$ & $<10$ & - \\
\hline
\end{tabular}

One of pellet fuel standards was selected for sample pellet fuel testing. The selected pellet fuel standard was PFI standard, the pellet fuel standard of United State [19]. The research selected this standard because the PFI standard has more detail about the pellet fuel quantities and refer the methodology of pellet fuel qualities testing form ASTM standard. In Thailand has the set of ASTM standard book in university libraries and Industrial standards office, ministry of Industry. So, it was easy to find and use for this research.

The over view of the research was shown in Fig. 1.

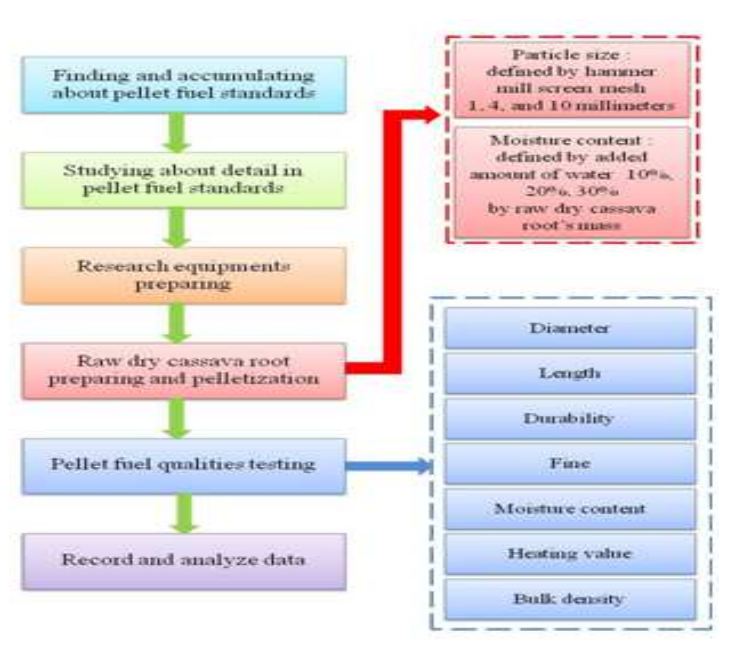

Figure 1. The over view of the research map. 


\subsection{Pellet Fuel Samples Preparing and Qualities Testing}

\subsubsection{Pellet Fuel Samples Preparing Processes}

Pellet fuel samples were made by flat die pellet mill. The raw material was cassava root that had original moisture content about $10.6 \%$ by mass (dry basis). First step, cassava roots were shredded by shredding machine. Second step, many pieces of cassava roots were taken to reduce their size into smaller size by hammer mill. They were reduced to 3 sizes by by hammer mill screen size : 1 , 4, and $10 \mathrm{mi}-$ limeters. Third step, cassava roots from second step were mixed with water by amount of it by mass of cassava roots (10\%, $20 \%$, and $30 \%$ by mass). Forth step, mixed materials were compressed by flat die pellet mill. The last step, after finished cassava root pellet fuel samples came out from pellet mill might be cooled by air and kept in moisture protection bag. The cassava root pellet fuel samples had total 9 samples as shown in Table 3. All the processes of cassava root pellet fuel samples preparing were concluded in Fig. 2.

Table 3. The cassava root pellet fuel samples.

\begin{tabular}{ll}
\hline Pellet fuel sample & $\begin{array}{l}\text { Mixture of raw cassava root and water for cassava } \\
\text { root pellet fuel forming }\end{array}$ \\
\hline Sample 1 & $\begin{array}{l}\text { Particle from screen mesh } 1 \mathrm{~mm}+\text { water } 10 \% \text { by mass } \\
\text { raw cassava root }\end{array}$ \\
Sample 2 & $\begin{array}{l}\text { Particle from screen mesh } 1 \mathrm{~mm}+\text { water } 20 \% \text { by mass } \\
\text { raw cassava root }\end{array}$ \\
Sample 3 & $\begin{array}{l}\text { Particle from screen mesh } 1 \mathrm{~mm}+\text { water } 30 \% \text { by mass } \\
\text { raw cassava root }\end{array}$ \\
Sample 4 & $\begin{array}{l}\text { Particle from screen mesh } 4 \mathrm{~mm}+\text { water } 10 \% \text { by mass } \\
\text { raw cassava root }\end{array}$ \\
Sample 5 & $\begin{array}{l}\text { Particle from screen mesh } 4 \mathrm{~mm}+\text { water } 20 \% \text { by mass } \\
\text { raw cassava root }\end{array}$ \\
Sample 6 & $\begin{array}{l}\text { Particle from screen mesh } 4 \mathrm{~mm}+\text { water } 30 \% \text { by mass } \\
\text { raw cassava root }\end{array}$ \\
Sample 7 & $\begin{array}{l}\text { Particle from screen mesh } 10 \mathrm{~mm}+\text { water } 10 \% \text { by } \\
\text { mass raw cassava root }\end{array}$ \\
Sample 8 & $\begin{array}{l}\text { Particle from screen mesh } 10 \mathrm{~mm}+\text { water } 20 \% \text { by } \\
\text { mass raw cassava root }\end{array}$ \\
Sample 9 & $\begin{array}{l}\text { Particle from screen mesh } 10 \mathrm{~mm}+\text { water } 30 \% \text { by } \\
\text { mass raw cassava root }\end{array}$ \\
\hline
\end{tabular}

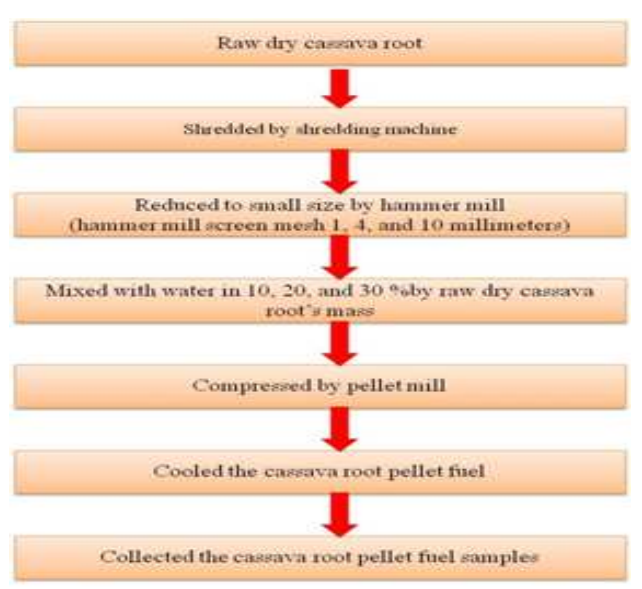

Figure 2. The processes of cassava root pellet fuel samples preparing.

\subsubsection{Pellet Fuel Sample'S Qualities Testing}

The pellet fuel sample's testing tested the pellet fuel qualities: diameter, length, moisture content, durability, fine, heating value, and bulk density. The pellet fuel qualities testing followed PFI standard testing methods [2], [18].

Diameter testing followed PFI standard method. In the testing processes, the pellet fuel samples were selected about 5 pieces for diameter measuring by venire caliper. The venire caliper had the precision about 0.001 inch $(0.02$ millimeters). The results from measuring were averaged and recorded [19].

Length testing followed PFI standard method. The pellet fuel samples were selected about 2.5 pounds (1.13 kilograms) and measured by 0.001 inch-precision venire caliper This testing wanted the value of more than 1.5 inch - pellet fuel's percentage from selected pellet fuel samples [19].

Moisture content testing followed ASTM E 871-72 method. The result of this measuring wanted to record about moisture content in pellet fuel samples on percentage (dry basis) [20].

Durability testing followed PFI standard method. The pellet fuel samples were put amount of $500 \pm 10$ grams into pellet fuel durability testing machine. The testing machine rotated about $50 \pm 2$ rounds/minute for 10 minute. In this testing wanted the value of pellet durability index (the percentage of none broken pellet fuel samples from tested pellet fuel samples) [19].

Fine testing followed PFI standard method. The pellet fuel samples were shaken on $1 / 8$ screen mesh by 10 times-side to side shaking. This testing recorded about mass percentage of fine in tested pellet fuel samples [19].

Heating value testing followed ASTM E 711-87 method. The result of this measuring wanted to record about heating value of tested pellet fuel samples [21].

Bulk density testing followed ASTM E 873 method. The testing wanted to record and calculate about the value of pellet fuel sample density. This value was the mass in grams per the volume in cubic centimeters [22].

The testing methods was repeated three times for pellet fuel sample and an average was taken. All results from testing were analyzed by statistical evaluation.

\section{Result and Discussion}

The results from the recorded data analyzing were summarized in Table 4. which shown the values of cassava root pellet fuel samples testing.

Particle size and moisture content of cassava root didn't influence to diameter and length of all cassava root pellet fuel samples because these parameters were defined by holes of pellet mill's die.

Almost cassava root pellet fuel samples had the values of durability passed PFI standard. S1 in Table 2. was smallest particle size and little amount of water that had bad pellet fuel form. The value of it's durability was lower than PFI standard. In the case of S7 was same result because it had biggest particle size and little amount of water. 
All cassava root pellet samples had little amount of fine and less than the PFI standard's definition because they had capability to form pellet fuel. So, the particle size and moisture content of cassava root didn't non-significantly influence to cassava root pellet fuel's quality.

The heating value of all cassava pellet fuel samples had in range of $16-18 \mathrm{MJ} / \mathrm{kg}$ because they were same type of raw material.

Table 4. The summarized result of cassava root pellet fuel samples's qualities testing.

\begin{tabular}{|c|c|c|c|c|c|c|c|}
\hline Pellet fuel standards & $\begin{array}{l}\text { Diameters } \\
(\mathrm{mm})\end{array}$ & $\begin{array}{l}\text { Length }(\% \text { of } \\
\text { longer than } \\
38.10 \mathrm{~mm})\end{array}$ & Durability (\%) & Fine $(\%)$ & $\begin{array}{l}\text { Bulk density } \\
\text { (MJ/kg) }\end{array}$ & $\begin{array}{l}\text { Moisture con- } \\
\text { tent }(\%)\end{array}$ & $\begin{array}{l}\text { Heating value } \\
\text { (MJ/kg) }\end{array}$ \\
\hline S1 & 6.02 & 0 & 94.73 & 0.08 & 644.50 & 7.70 & 16.99 \\
\hline S2 & 6.03 & 0 & 98.72 & 0.02 & 683.03 & 8.81 & 16.75 \\
\hline S3 & 6.06 & 0 & 99.16 & 0.02 & 705.18 & 10.47 & 16.76 \\
\hline S4 & 6.16 & 0 & 96.17 & 0.07 & 644.98 & 6.21 & 17.48 \\
\hline S5 & 6.08 & 0 & 99.32 & 0.04 & 676.50 & 8.75 & 16.89 \\
\hline S6 & 6.06 & 0 & 97.89 & 0.10 & 671.46 & 6.34 & 17.62 \\
\hline S7 & 6.08 & 0 & 93.89 & 0.10 & 625.80 & 8.82 & 17.76 \\
\hline S8 & 6.04 & 0 & 98.50 & 0.05 & 654.26 & 9.48 & 17.81 \\
\hline S9 & 6.00 & 0 & 99.15 & 0.08 & 697.69 & 8.54 & 16.93 \\
\hline USA (PFI) & $5.84-7.25$ & $\leq 1.0$ & $\geq 95$ & $\leq 1.0$ & $596.6-722.2$ & $<10$ & - \\
\hline
\end{tabular}

In the case of bulk density, moisture content and particle size in this research didn't effect on this properties because the pelletization was made from the same flat die pellet mill. So, the cassava root pellet fuel samples had same range of pellet fuel's bulk density.

The last quality, moisture content of cassava root pellet fuel samples weren't impacted by particle size and moisture content. The small particle size well absorbed water better than big particle size. So, remained amount of water in the mixture big particle size with water was evaporated by pellet mill's die. The moisture content of that mixture was low.

From the testing results, can compare with prior research that explained about the influence of moisture content and particle size on pellet fuel. The optimum moisture content for wood species was found to be $5-10 \%$ by mass, while it was $10-20 \%$ by mass for agricultural grasses [13]. The optimum particle size depends on densification processes. The pellet production particles were usually below 5 millimeters in diameter [13]. So, the moisture content and particle size in this research didn't influence to cassava root pellet fuel's quantities because the range of moisture content and particle size in this research was in the optimum range.

\section{Conclusion}

The pellet fuel standards in the world were found that used in western countries. These countries used pellet fuel for heater and other household equipments.

Moisture content and particle size of cassava root didn't have effect on cassava root pellet fuel's qualities : diameter, length, durability, fine, pellet fuel's moisture content, heating value, and bulk density. So, all cassava root pellet fuel samples passed each regulation values of pellet fuel standard inconsiderably.

\section{Acknowledgements}

This research has been funded from Graduate School and department of Mechanical Engineering, Silpakorn University, Thailand.

\section{References}

[1] Spatial biomass potential of Thailand in 2009. Information on http:// www.dede.go.th, (cited 17.02.2013).

[2] Zhijia Liu, Xing'e Liu, Benhua Fei, Zehui Jiang, Zhiyong Cai, and Yan Yu, "The properties of pellets from mixing bamboo and rice straw," Renewable Energy 55, pp. 1-5, 2013.

[3] Anton Leander Schuller, "Developing a Wood Pellet Fuel Sector in South Yorkshire," 2004.

[4] Brigitte Hahn, "Existing Guidelines and Quality Assurance for Fuel Pellets," 2004.

[5] A. Garcia-Maraver, V. Popov, and M. Zamorano, "A review of European standard for pellet quality," Renewable Energy 36, pp. 3537-3540, 2011.

[6] Samson, R., P. Duxbuy, M. Drisdelle, and C. Lapointe, “As- 
sessment of Pelletized Biofuels,” 2000.

[7] Gil, M.V., P. Oulego, C. Pevida, J.J. Pis, and F. Rubiera, "Mechanical durability and combustion characteristics of pellets from biomass blends," Biomass Technology 101, pp. 8859-8867, 2010.

[8] Stahl, M., K. Granstrom, J. Berghel, and R. Renstrom, "Industrial processes for biomass drying and their effects on the quality properties of wood pellets," Biomass and Bioenergy 27, pp. 621-628, 2004.

[9] Zamorano, M., V. Popov, M.L. Rodriguez, and Garcia-Maraver, "A comparative study of quality properties of pelletized agricultural and forestry lopping residues," Renewable Energy , pp. 1-8, 2011.

[10] Theerarattananoon, K., F. Xu, J. Wilson, R. Ballard, L. Mckinney, S. Staggenborg, P. Vadlani. Z.J. Pei, and D. Wang, "Physical properties of pellets made from sorghum stalk, corn stover, wheat straw, and big bluestem," Industrial Crops and Products 33, pp. 325-332, 2011.

[11] Nalladurai Kaliyan and R. Vance Morey, "Factor affecting strength and durability of densified biomass products," Biomass and Bioenergy 33, pp. 337-359, 2009.

[12] Wolfgang Stelte, Jens K. Holm, Anand R. Sanadi, Soren Barsberg, and Jesper Ahrenfeldt, "Fuel pellets from biomass : The importance of the pelletizing pressure and its dependency on the processing conditions," Fuel 90, pp. 3285-3290, 2011.

[13] Wolfgang Stelte, Anand R. Sanadi and others, "Recent Developments in Biomass Pelletization - A Review," BioResourse 7, pp. 4451-4490, 2012.

[14] Dan Bergstrom, Samanuel Israelsson, Marcus Ohman, Sten-Axel Dahlqvist, Rolf Gref, Christoffer Boman, and Iwan Wasterlund, "Effect of raw material particle size distribution on the characteristic of Scots pine sawdust fuel pellets," Fuel Processing Technology 89, pp. 1324-1329, 2008.

[15] Gilbert, P., C. Ryu, V. Sharifi, and J. Swithenbank, "Effect of process paprameters on pelletisation of herbaceous crops," Fuel 88, pp. 1491-1497, 2009.

[16] Tore Filbakk, Geir Skjevrak, Olav Hoibo, Janka Dibdiakava, and Raida Jirjis, "The influence of storage and drying methods for Scots pine raw material on mechanical pellet properties and production parameters," Fuel Processing Technology 92, pp. 871-8778, 2011.

[17] Jarinee Jongpluempiti, and Kiatfa Tangchaichit, "Comparison proximate analysis and heating value between cassava rhizome and perennial wood," Advanced Materials Research Vols. 415-417, pp. 1693-1696, 2012.

[18] Jerome H. Cherney, Vijay Kumar Verna, "Grass pellet Quality index: A tool to evaluate suitability of grass pellets for small scale combustion system," Applied Energy 103, pp. 679-684, 2013.

[19] Pellet Fuels Institute Standard Specification for Residential/Commercial Densified, 2010.

[20] ASTM International. (2010). "E 871-82: Standard Test Methods for Moisture Analysis of Particulate Wood Fuels." Annual book of ASTM Standards, 11.06: 107-108.

[21] ASTM International. (2010). "E 711-87: Standard Test Methods for Gross Calorific Value of Refuse-Derived Fuel by the Bomb Calorimeter." Annual book of ASTM Standards, 11.04: 734-741.

[22] ASTM International. (2010). "E 873-82: Standard Test Method for Bulk Density of Densified Particulate Biomass Fuels." Annual book of ASTM Standards, 11.06: 112-113. 